\title{
Social Pedagogy as a Necessary Basis for Teachers Training in Greece
}

\author{
Vassilis Pantazis \\ Department of Early Childhood Education \\ University of Thessaly, Greece \\ https://orcid.org/0000-0003-0915-7752 \\ Despoina Styla \\ Department of Early Childhood Education \\ University of Thessaly, Greece \\ https://orcid.org/0000-0001-9354-7125
}

\begin{abstract}
This paper aims to examine the importance of social pedagogy theory and practice throughout teachers' continuing training in Greece. Teaching is a demanding job that cannot be complete, unless the teacher is scientifically trained and that's why we argue, according to relevant scientific researches, that social pedagogy theory, through practical application, can be very constructive, for this purpose. Thus, the authors initially attempt to go through a general overview of social pedagogy, to inform teachers about what social pedagogy is, about the theory, the content and objectives of social pedagogy. Moreover, the research method of the study is a systematic review and a thematic analysis of sociological and other scientific studies relevant to social pedagogy and teachers training, conducted/found on the Web. According to the results, first of all, considering the major responsibility of classroom teachers for continuing training, it's important for teachers to be social pedagogues, since the main principles of social pedagogy can supply them with the ability to deal with problems and difficulties raised in the classroom. Secondly, that importance is growing, if we consider that teachers attempt for a holistic teaching/didactic approach, following social pedagogy's principles, is reflected in children's ability for social and emotional development, for healthy relationships, for achieving wellbeing and becoming complete citizens. Finally, the necessity of this research is growing, if we consider that especially nowadays in Greek society, students face many social problems, the majority of which occur due to the current economic crisis (such as bullying, poverty, racism) and that's why the spread of social pedagogy's theory and practice in Greek teaching/educational community, is of high essentiality and can be achieved through teachers continuing training.
\end{abstract}

Keywords: teachers; continuing training; social pedagogy; social pedagogues; Greek society 


\section{Introduction}

The founding of Social Pedagogy in Germany depicts the enormous socioeconomic problems that this country was experiencing in the 19th century due to the industrial revolution, which gave birth to the need for "resistance" from society and especially from the lower social class, so that social changes can take place. Thus, more emphasis was placed on the social functioning of education (Hämäläinen, 2003).

As a scientific field, social pedagogy appeared in the 20th century, when the German philosopher Paul Natorp (1854-1924), published, in 1899, the book 'Sozialpädagogik: Theorie der Willensbildung Auf der Grundlage der Gemeinschaft' (Social Pedagogy: The Theory of Educating the Human Will into a Community Asset) (Eriksson, 2010). Specifically, Natorp (1904, p.94) as mentioned in Kornbeck and Jensen (2012, p.201) argued that "teachers should always consider the interaction between the social aspects of education and the educational aspects of social life".

There are some theorists of the 19th and 20 th century whose philosophy affected Social Pedagogy such as Karl Mager (1810-1858) and Friedrich Distersweg (17901866) who believe in education's social mission and Herman Nohl (1879-1960) who argued that pedagogical intervention should focus on social help, based on love (Schugurensky \& Silver, 2013).

Social pedagogy's relationship with the area of education is narrow, according to what Moss and Petrie (2019 p. 402) say about that issue. They claim that social pedagogy is capable of "spanning and infusing" all the areas that work with people of all ages, including schools of all levels. Also, in some European countries, social pedagogy is the subject of undergraduate and postgraduate studies (Petrie, 2013). In Greece, at this point, there have also been developed higher education study programs, dealing with the subject of social pedagogy, such as: 1) the undergraduate course called 'introduction to social pedagogy' at the University of Thessaly, Department of Early Childhood Education, 2) the undergraduate course called 'Socio-educational approaches in primary school' at the University of West Macedonia, Department of Primary Education, 3) the postgraduate course, called 'Social Neuroscience, Social Pedagogy and Education' at National and Kapodistrian University of Athens (EKPA) (Kontogianni, 2019). However, there is a great need that the range of those education programs about social pedagogy should become wider.

Moreover, although Greek university students start becoming familiar with social pedagogy theory (to clarify the theoretical basis, such as learning a theoretical introduction to social pedagogy, including a history of ideas, basic concepts, etc.), during their studies at the university, there is no research evidence (research studies) that they continue with this, during their continuing training. We argue, that there is a great need, that teachers around the world rediscover the concept of social pedagogy, during their continuing training. And this is very crucial, especially for Greek teachers, as Greek society is currently affected by an economic crisis that also translates into a social crisis (Kyridis, Christodoulou, Vamvakidou \& Paulidis-Korres, 2015). Thus, this paper aims, through literature review, to emphasize the importance of the social pedagogy theory and practice, throughout continuing training of teachers and especially Greek teachers. 


\section{Methodology}

A systematic review was used in the collection of texts, included in this study. Systematic review is "a form of literature review, which involves identifying, synthesising and assessing all available evidence, quantitative and/or qualitative, in order to generate a robust, empirically derived answer to a focused research question" (Mallett, Hagen-Zanker, Slater \& Duvendack, 2012, pp. 445-446). Moreover, according to Green, Johnson and Adams (2006, p.104) "authors of systematic reviews attempt to obtain all original research studies published on the topic under study by searching in multiple databases, performing hand searches and contacting authors of previously published research".

After examining the offered possibilities for selecting open accessed articles, online books, conferences proceedings, dissertations/theses and reports relevant to social pedagogy, we decided to limit the research to the Education Resources Information Centre (ERIC), to Google Scholar database, to Scopus database, to Web of Science (WoS), to Research Gate network and Akademia.edu network of professionals and scientists.

Great effort has been made to perform a scientific procedure, to meet academic standards of high quality. The following inclusion criteria were conducted, to select texts in the review: (1) deal with social pedagogy (which were the first Keywords search), (2) deal with teachers training (which were the second Keywords search), (3) be published in peer-reviewed journals, (4) be published during the period 2000-2020, (5) written and published in the English Language, (6) the terms 'social pedagogy' or 'social pedagogues' must appear clearly in the titles, (7) the term 'teachers training' must appear in the titles, separate or combined to the social pedagogy term, (8) avoid texts referring to social work and social workers, a distinct/separate scientific field (9) avoid comparative studies of social pedagogy and social work, as they are irrelevant to our study's topic.

Using the above search criteria on Web (our study's query run between September 2019 and December 2019) we obtained 85 articles, 3 on-line books, 3 theses, 4 reports, that were eligible for thematic analysis, which is a method for identifying, analysing, organizing, describing, and reporting themes found within a data set (Bryman, 2012). To use only those of the 85 articles that correspond to our main research goal, the following exclusion criteria were used: (1) exclude journals that include no references to the social pedagogy's connection to practice and the general benefits occurred by this connection, (2) to exclude studies referring to teachers training and to the increase of their professionalism, which are the majority of studies appearing, when one types on the Web the Keywords 'teachers training', (3) to exclude the major number of studies that examine the history of social pedagogy in different countries, which is irrelevant to our study.

To continue to literature review, we first analyse the term social pedagogy, because when the discussion comes to what social pedagogy is, there is a great misunderstanding, as it is a complex field. A field which tries to combine the principles of social, psychological, educational, etc. sciences (Cameron \& Moss, 2011), to prevent and fight mostly social problems (such as social exclusion), in different spaces and ages (as schools of all levels, institutions of old age fostering, supporting domes for youth, etc.). Social pedagogy doesn't give prescriptions for 
the solutions, but tries to deal holistically with the situation, with an emphasis on strengthening human relationships and promoting the idea of how to develop/promote a healthy way to deal with life, to gain a mental and psychological balance, to become complete personalities, ready to stand on their feet. That's why, social pedagogues cooperate with all the factors that affect one's life (such as the parents, the family, the topical residence, the doctors, etc.).

\section{Literature review}

\subsection{Social pedagogy as a concept}

The term pedagogy is derived from the Greek word 'pais', meaning child and the word 'agein', meaning to bring up (Eichsteller \& Holthoff, 2011). The concept of social pedagogy concerns the relationship between society and education and the way one affects the other (Petrie, Boddy, Cameron, Wigfall \& Simon, 2006). According to ThemPRA (2019) some of the main foundations of social pedagogy theory are the following: raise the feeling of empathy, emphasize the need for protection of human rights, enable people to achieve self-autonomy and self reflection, to be able enough to change and improve their own lives and generally speaking, to understand the enormous necessity for the protection of vulnerable social groups. Moreover, taking into consideration Hämäläinen (2003) claim that social pedagogy is not a strict teaching method, we understand that an education system with a social pedagogical orientation does not only care for the strict education and cognitive performance of their students, with strict teaching prescriptions, but also pursues to educate all individuals related to the school community (students, parents, teachers, topical society etc.) to strive for a better world, for a better society, with less social discriminations (Pantazis, 2012).

Additionally, the drafters of the 'Radisson Report' (Social Education Trust, 2001, pt. 4.1) provide a list of nine characteristics of Social Pedagogy. Some of these are: social pedagogues/educators view a child's situation holistically, education cares for social competencies and morals values learning, putting in the center the development of healthy human relations.

Through prosperity and learning, it aims at complete development and integration of each individual, within his social context, considering as a given that all human beings have the potential to be valuable and responsible members of society, as long as society caters to their inclusion, rather than exclusion. That is why social educators deal with a wide range of ages, from the first years of life to old age, and social pedagogy can be applied to different contexts, such as early childhood, family support, drug-addicted support, elderly support, teenagers support, disability services, support for imprisoned, etc. with priority the active participation of those involved (Petrie \& Cameron, 2009).

Furthermore, according to Eichsteller and Bradt (2019), there are various reasons why social pedagogy is suitable for educational and social practices, such as the following: it gives attention to the enhancement of human relationships, believes that every human being has capabilities and talents and should have the opportunities to unwrap those, emphasizes dialogue and civilized communication, strikes at human problems, such as poverty, offers a specific framework that can be very helpful to a broad range of professionals, raises the 
motivation of professionals. We should add here that the last reason is extremely crucial for teachers' jobs, as according to Carson and Chase (2009), teacher's motivation is an essential factor that affects and enforces classroom effectiveness.

To summarize the substance of all the above references, can be compacted in Boddy, Cameron, Moss, Mooney, Petrie and Stathams (2005) following words:

"Social pedagogy is an approach: in which learning, care, health, general wellbeing, and development are viewed as totally inseparable, a holistic idea summed up in the pedagogical term 'upbringing'. The pedagogue as practitioner sees herself as a person in relationship with the child as a whole person, supporting the child's overall development" (Boddy et al, 2005, p. 3).

\subsection{Social pedagogy's Connection to Practice}

As Hämäläinen (2003) claims we can see social pedagogy both as a practice and a democratic philosophical approach. To understand the connection of social pedagogy to practice we should bring to mind two metaphorical parallelisms of social pedagogy, firstly as a tree and secondly as a diamond. According to Eichsteller and Holthoff (2012) social pedagogy as a tree finds its roots in the works of scientists in different scientific fields, such as education, philosophy, sociology, and psychology. The trees flourishment depends on the gardeners (social educators/pedagogues) who use many tools for this purpose (a person's well-being) such as teamwork, communication, etc. The Diamond Model (Figure1) is another metaphor parallelism of social pedagogy. The image of the diamond symbolizes the idea that there is a diamond within all of us, that we are all precious and have a rich variety of knowledge, skills, and abilities. The Diamond Model outlines four aims of social pedagogical practice: to enhance wellbeing and happiness, to enable holistic learning, to develop relationships, and to increase a sense of empowerment. These aims are brought to life through positive experiences (Thempra, 2019; Eichsteller \& Holthoff, 2011).

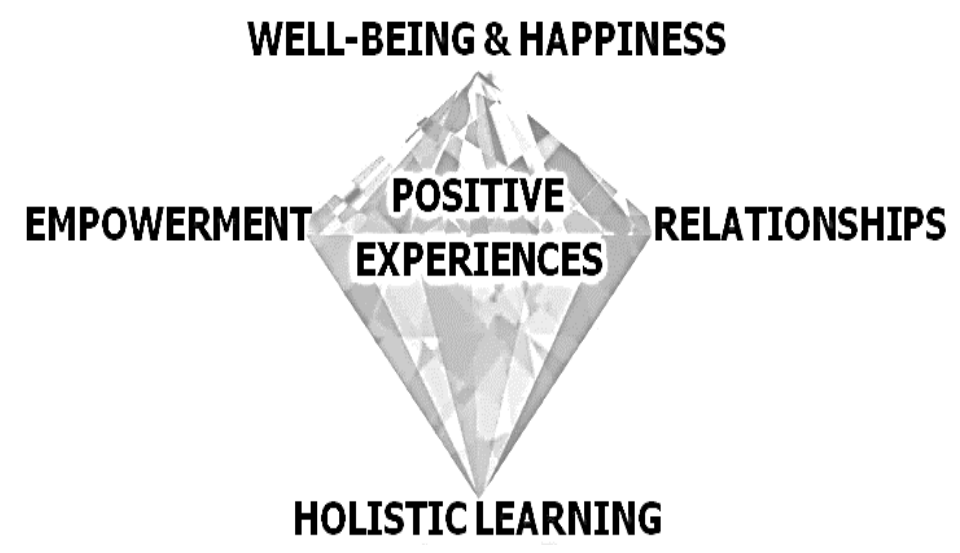

Figure 1: The Diamond Model (Eichsteller \& Holthoff, 2011)

Social pedagogy in practice offers a set of organized pedagogical actions that seek to influence and change social and educational mechanisms (Petrie et al., 2006; Hämäläinen, 2012; Stephens, 2013). 
Taking into consideration the above literature review, at this point of our study, we suggest some of the following application examples of social pedagogy in a school classroom, such as:

a) Humanitarian action that promotes the development of students emotional and social skills,

b) the fight of critical incidents (e.g. violence and victimization, racism in the classroom) with the development of socio-educational programs, in cooperation/collaboration with social institutions and special scientists/experts,

c) the organization of experiential seminars for the parents about social issues,

d) the participation in experiential socio-educational programs (topical or international) carried out in schools, organized by the government, aiming at highlighting the socio-pedagogical dimensions (of the many forms) of the heterogeneity, the uniqueness and identity of each person (in collaboration with other teachers/colleagues),

e) the organization of educational activities inside and outside the school,

f) the group meetings and events with parents (celebrations, etc.),

g) the student visits to various institutions (some Greek institutions are: the Refugee Hospitality Centers, the Child's Smile, the SOS Villages, etc.) that develop social pedagogical activity.

The application of the above actions requires teachers with emotional stability, emotional abilities, and emotional intelligence in pedagogical interaction, as it is emphasized by many studies. When the relationship between teachers and students is charged with negative emotions, for various reasons, communication is disrupted and students get disappointed (Konstantinou, 2004).

Moreover, the role of the modern teacher is demanding. Essentially, in terms of the cognitive part of teaching, the teacher must help in the synthesis and analysis of knowledge, expand students' critical thinking, and their productivity. But most important of all, the teacher must possess emotional intelligence, as according to Rogers (1983) respect, empathy, and authenticity are the three basic elements of communication with the student.

Similarly, Fontana (1994) and Brown (2004) argue a teacher must take on modern roles as: - mediator between knowledge and the student, $\bullet$ humanist and democrat, $\bullet$ counselor and discreet driver, $\bullet$ psychologist, sociologist, educator.

Moreover, Jacobs (2001), in a common context, believes that the human skills a teacher should own, are divided into the following categories: A) Counseling skills: 1 . help others solve problems, 2 . to build trust and be open with their fellow human beings, 3 . to give advice effectively, 4 . help others better understand themselves. B) Communication skills: 1 . to present ideas with objective way, 2 . to present ideas and information comprehensively, 3. to manage the speech accurately. C) Leadership skills: 1. to inspire confidence and respect in others, 2. to organize effective groups, 3 . to be able to cooperate with "difficult" people. D) Educational skills:1. help others gain knowledge and different skills, 2. activates others to present them. 
To summarize, according to Anderberg (2020) the review shows the global differences as it comes to the role of social pedagogues in schools (about their missions, goals, status, roles, functions, tasks, activities). The central mission in most countries is to fight the exclusion of pupil groups or individuals with problems. Another frequent mission is the prevention of serious problems such as bullying, violence, and drug use. Moreover, there is an orientation towards upbringing with a democratic manner and active social participation, of all students.

\subsection{Teachers continuing training}

At this point in the literature review, we find it necessary to refer to the meaning of teachers' continuing training. First of all, training is defined as:

"The set of measures and activities adopted and implemented to improve and develop academic, practical and personal or professional knowledge, skills, abilities, and interests of teachers during their career" (Mavrogiorgos, 1996, p. 86).

Moreover, according to OECD (2010):

"These activities can be very heterogeneous: dissemination conferences, workshops (preparation to new subject-matter content), school-based activities (study groups, courses), personal teacher development (individual activities outside of schools)" (OECD, 2010, p.7).

Additionally, according to Papadopoulou and Bagakis (2015), as it is mentioned in Law 3879/2010 (The Development of Life-long Learning), a teacher's training can be evolved through:
“a) access to opportunities for continual professional development, b) the creation of flexible learning paths, c) development of open education and e-learning, d) branching out into non-formal and informal forms of learning, e) use of new teaching and learning technologies from educational and research institutes and other providers, f) creation of networks for innovation at both a local and regional level, g) activities for the development of all the educational staff, $h$ ) individualized programs "any time and at any place" (Papadopoulou \& Bagakis, 2015, p.427).

Many studies place importance to in-service training that can take place in the school environment, as according to Mavrogiorgos (1999), the in-school training is more reliable than the out-of-school training, because it meets teachers' needs, combines the theory with the practice, raises the school's quality level and contributes to the school collaboration with the other schools and with the field of scientific research.

According to Eurydice (2019) formal continuing training of teachers of all levels is usually done by expertized institutions (inspected by the government for their quality) with high standards, at a national level, aiming at teachers' professional development, career evolution, acquisition of competencies and development of capabilities to cope with change, difficulties and unpredictable situations during their careers. 
In summary, in Greece, according to Asimaki, Sakkoulis and Vergidis (2016), Papagueli - Vouliouris (1999), Papastamatis and Panitsidou (2008), in-service teacher training can be tacked in the following periods: a) 1880 - 1977: the establishment of the "Didaskaleion", a training institute, b) 1977 - 1992: the period of professional teacher training schools for elementary and secondary teachers called "SELDE-SELME", c) 1992 - 1995: the Regional Training Centres (known as PEKs), d) 1995 - 2011: the "European" period, the implementation, under Law 2986/2002, of the Teacher Training Agency (known as OEPEK), which today is replaced by the Institute of Education Policy (known as IEP).

\subsection{The value of teachers' continuing training}

Especially nowadays, at the end of one's studies, there is an enormous need for lifelong learning, since the field of human knowledge is not static, but is in dynamic development (Papadopoulou \& Bagakis, 2015). Teachers' professional development should begin during their studies and continue during their life. The continuing training of teachers should be characterized by flexibility and adaptability, as new pedagogical and socio-cultural data are constantly emerging and teachers should be upgraded. We argue that even if they have received a quality initial teacher education, they need to be trained continually, to know how to manage the difficulties and problems to which they are faced.

Therefore, it is beneficial for teachers to improve/update their skills, because benefits are enormous according to the results of different researches. For example, according to Ajokou (2013), in-service continuing training: 1) enforces teachers Mental Health to be able to tolerate the disturbances that may occur in a classroom, 2) broadens their social contacts as they have many chances to socialize with other colleagues during their training, 3) grows the willingness to know more about the profession, to catch up with the new and latest findings in education, 4) gives opportunities for advancement on the job. Everybody wants to get a better position, such as becoming headmasters, counselors etc. All these positions are possible only for those who go on and strive to update through continuing training.

Moreover, we embrace the point of view of Boudersa (2016) that teacher continuing training and professional development should be democratic enough, so as not to impose on the consolidation of teachers' perceptions and established knowledge about a given teaching methodology. Teacher training and professional development should aim at the fundamental change of teachers' practices, which, in turn, will lead to the improvement of their educative effectiveness.

Teachers at all levels of education need to be always trained if they are to improve their practices in their classes. Such training programs will help teachers to improve their knowledge of the subject they teach and the social skills they need in the classroom. There is no doubt that teachers will benefit from professional development only if that development contains activities that focus on highquality content. And those activities should be organized by scientists/experts, during the training programs and courses, so that the teachers' demands get satisfied and raise their willingness to keep walking on this long life- learning path. 


\section{The results of the analysis}

The results of the thematic analysis can be detected in the following points. First of all, it seems that Greek teachers get some information about social pedagogy theory and practice during their university studies, but in Greece we argue that there is a crucial/substantial need for those programs to be expanded, as the official number of those university studies, mentioned above (see part 1. Introduction) is extremely poor.

Secondly, is of great importance for teachers to come up with those principles of social pedagogy throughout their whole career, especially nowadays in modern Greek society, where students face many social problems, the majority of which occur due to the current economic crisis such as bullying, the poverty the economic crisis brings, racism (due to cultural differences that refugees face), etc. That importance is growing, if we consider that teachers attempt for a holistic teaching/didactic approach, following social pedagogy's principles, is reflected in children's ability for social and emotional development, for healthy relationships, for achieving wellbeing and becoming complete citizens (see 3.1).

Thirdly, as the role of the modern teacher is demanding and as according to Rogers (1983) it's very important that teachers not only possess knowledge, but emotional intelligence too (see 3.2) it seems to be a grave need to update and gain more familiarity with the social pedagogy principles during their continuing training and professional development and not only during their university studies. This is because, according to Kyriakou, Stephens, Avramidis and Werlers (2011) student teachers, although tend to be open-minded to new initiatives, they often have second thoughts about how prepared they are to concur to school's progress and the application of innovative methods. In short, according to the citation of the above bibliography social pedagogy theory and practice it's an ideal situation and an opportunity for all teachers to enhance their emotional and social skills.

Moreover, considering the major responsibility of classroom teachers for continuing training (as we mention above at 3.4), teachers, among other things, throughout their training and professional development, should be or become social pedagogues, since the main principles of social pedagogy can supply them with the ability to deal with problems in the classroom (Eurydice, 2019).

Generally speaking, the main principles of social pedagogy can supply them with the ability to contribute to the improvement of the Greek education system. Especially in Greece, unfortunately, that education system: "Is made to create collegialities through "suppressive" actions and practices primarily attributed in the range of assessment and school competition" (Kyridis, Papadakis, Tourtouras, \& Lytrivi, 2016, p. 12) and we agree with Kyridis, Christodoulou, Vamvakidou and Paulidis-Korres (2015) who argue that: "We need more holistic educational activities, such as those that social pedagogy proposes, which are gentler than those of the formal education system" (Vamvakidou \& Paulidis-Korres, 2015, p.31).

At this point, we cannot skip the sad truth that in Greece there is a need to obtain a wider social pedagogy network (composed of experts), and take as an example the UK, where we find a wide social pedagogy network. Where, for instance, somebody can meet the following: a) the ThemPra, which is a social pedagogical 
enterprise, supporting the development of social pedagogy through scientific actions (http://www.thempra.org.uk/), b) the Social Pedagogy Professional Association-SPPA, which aims to support vulnerable social groups (https://sppa-uk.org/) and c) the Social Pedagogy Development NetworkSPDN, which tries to unite the social pedagogues and organize relevant activities (http://www.thempra.org.uk/spdn/).

\section{Discussion and conclusion}

In this current paper we stress the need for teachers to get acquainted with the theory and practice of social pedagogy and attain consideration of the main principles of social pedagogy, during their training, their journey of discovery, because teachers are one of the three groups of adults involved in the education of children (the other two groups are the family members and other professional such as social workers, psychologists, etc.). Especially, teachers have the potentiality to guide children to become complete citizens and integrated personalities (Kyriakou, Avramidis, Stephens \& Werler, 2011). Moreover, there is a feeling, that more than ever in Greece, we need open-minded teachers who will adopt and will be scientifically trained and able to apply social pedagogy in their classrooms, and this can only be achieved, throughout their continuing training, by expertized educators and trainers. Coming to the end of our study we can summarize the substance of the above literature review and analysis, to the argument that there is a diamond within all of us, we are all precious and have a rich variety of knowledge, skills, and abilities (Eichsteller \& Holthoff, 2011). This is an encouraging aspect, that teachers should have in mind during their lifelong learning path.

Finally, the present study has some important limitations, such as the lack of interviews (or other research methodologies) conducted with Greek teachers, to examine the way they think about social pedagogy and to examine if they feel prepared for the direct practice of the main principles of social pedagogy in education. We hope that these limitation, will be the trigger for further studies and research.

\section{References}

Anderberg, M. (2020). In search of a social pedagogical profession in schools. Missions and roles under reconsideration. International Journal of Social Pedagogy, 9(1), 1-19. https:// doi.org/10.14324/111.444.ijsp.2020.v9.x.001

Ajoku, L. I. (2013). Development of Teachers, Action Planning, and Utilizing 21st Century Skills in Nigerian Schools. Journal of Education and Practice, 4(15).

Asimaki, A., Sakkoulis, D., \& Vergidis, D. (2016). Searching for pedagogical practices for success at school for "all" the students: a sociological approach (in Greek). Step of Social Sciences, IZ(67).

Boddy, J., Cameron, C., Moss, P., Mooney, A., Petrie, P., \& Statham, J. (2005). Introducing Pedagogy into the Children's Workforce: Children's Workforce Strategy: A response to the consultation document. London: Thomas Coram Research Unit.

Boudersa, N. (2016). The Importance of Teachers' Training and Development Programs in the Algerian Educational Context: Toward Informed and Effective Teaching Practices. Expériences Pédagogic, 1. 
Brown, R. (2004). Social identity theory: past achievements, current problems, and future challenges. European Journal of Social Psychology, 30(6), 745-778.

Bryman, A. (2012). Social research methods. Oxford: Oxford University Press.

Cameron, C., \& Moss, P. (2011). Social pedagogy: current understandings and opportunities. In C. Cameron \& P. Moss (Eds.), Social pedagogy and working with children and young people: where care and education meet (pp. 7-32). UK: Jessica Kingsley. https:// doi.org/10.1080/00071005.2012.660337

Carson, R. L., \& Chase, M. A. (2009). An examination of physical education teacher motivation from a self-determination theoretical framework. Physical Education and Sport Pedagogy, 14, 335-353. https://doi.org/10.1080/17408980802301866

Eichsteller, G., \& Holthoff, S. (2011). Conceptual Foundations of Social Pedagogy: A Transnational Perspective from Germany. In C. Cameron, \& P. Moss, Social Pedagogy and Working with Children. UK: Jessica Kingsley Publishers.

Eichsteller, G., \& Holthoff, S. (2012). The Art of Being a Social Pedagogue: Developing Cultural Change in Children's Homes in Essex. International Journal of Social Pedagogy, 1, 30-45. https:// doi.org/10.14324/111.444.ijsp.2012.v1.1.004

Eichsteller, G., \& Bradt, L. (2019). Social Pedagogy as a Meaningful Perspective for Education and Social Care. Insight Report. Beaumaris: ThemPra.

Eriksson, L. (2010). Community development and social pedagogy: Traditions for understanding mobilization for collective self-development. Community Development Journal, 46(4), 403-420. https://doi.org/10.1093/cdj/bsq008

Eurydice/Eurybase, (2019). Continuing Professional Development for Teachers Working in Early Childhood and School Education. Retrieved from: https://eacea.ec.europa.eu/nationalpolicies/eurydice/content/continuingprofessional-development-teachers-working-early-childhood-and-schooleducation-61_en

Fontana, D. (1994). Managing Classroom Behaviour. USA: BPS Books.

Green, B. N., Johnson, C. D., \& Adams, A. (2006). Writing narrative literature reviews for peer-reviewed journals: secrets of the trade. Journal of chiropractic medicine, 5(3) 101-117.

Hämäläinen, J. (2003). The Concept of Social Pedagogy in the Field of Social Work. Social Work and Society, 1(1), 69-80. https://doi.org/10.1177/1468017303003001005

Hämäläinen, J. (2012). Social Pedagogical Eyes in the Midst of Diverse Understandings, Conceptualizations and Activities. International Journal of Social Pedagogy, 1(1), 316. https:// doi.org/10.14324/111.444.ijsp.2012.v1.1.002

Jacobs, R. L. (2001). Using human resource functions to enhance emotional intelligence. In C. Cherniss \& D. Goleman (Eds.), The Emotionally Intelligent Workplace (pp. 159181). San Francisco: Jossey-Bass.

Konstantinou, Ch. (2004). School Reality and Socialization of the student (in Greek). Athens: Gutenberg.

Kontogianni, E. (2019). Studies at social pedagogy. Retrieved from: https://www.socialpedagogy.gr/tag/academic-studies/

Kornbeck, J., \& Jensen, N. R, (2012). Social pedagogy for the entire lifespan. Bremen:

Europäischer Hochschulverlag GmbH \& Co.

Kyriakou, Ch., Avramidis, E., Stephens, P., \& Werler, T. (2011). Social pedagogy in schools: student teacher attitudes in England and Norway. International Journal of Inclusive Education, 17(2), 192-204. https:/ / doi.org/10.1080/13603116.2011.629689

Kyridis, A., Christodoulou, A., Vamvakidou I., \& Paulidis-Korres, M. (2015). Fighting Corruption: Values Education and Social Pedagogy in Greece in the middle of the 
Crisis. International journal of social pedagogy, 4(1), $24-42$. https:// doi.org/10.14324/111.444.ijsp.2015.v4.1.003

Kyridis, A., Papadakis, N., Tourtouras, Ch., \& Lytrivi, I. (2016). Social values, tansparency, and the Greek educational system in the era of the crisis. Attitudes of Greek university students. In the Proceedings of 1st international Conference in contemporary Social Sciences, Crisis and the Social sciences: new challenges and perspectives. Greece: University of Crete.

Mallett, R., Hagen-Zanker, J., Slater, R., \& Duvendack, M. (2012) The benefits and challenges of using systematic reviews in international development research, Journal of Development Effectiveness, 4(3), 445-455. https:// doi.org/10.1080/19439342.2012.711342

Mavroyiorgos, G. (1999). Training of teachers and training policy in Greece. In A. Reppa, S. Anthopoulou, \& S. Katsoulaki (Eds), Human Resource Management (pp. 123-131). Patra: Hellenic Open University.

Moss. P., \& Petrie, P. (2019). Education and social pedagogy: What relationship?. London Review of Education, 17(3), 393-405. https://doi.org/10.18546/LRE.17.3.13

OECD. (2010). Starting Strong II: Early Childhood Education and Care. France: OECD Publications.

Pantazis, V. (2012). Human Rights Education: Theory - Research. Athens: Diadrasis Editions.

Papadopoulou, M., \& Bagakis, G. (2015). Professional development of teachers in secondary education in Greece. An open and flexible learning environment or a confined and rigid education system. In the Proceedings of 3rd International Conference, ISNITE 2015, New Issues on Teacher Education (pp. 426-432).

Papagueli-Vouliouris, D. (1999). Evaluation of Teacher Education in Greece- a political demand of our time. Education Research Centre, Athens, TNTEE Publications, 2(2).

Papastamatis, A., \& Panitsidou, E. (2008). Educators \& professionalism in adult education: the KEE case. In the Proceedings of the 3rd International Conference of the Scientific Association of Adult Education: Adult Educators: their training and professionalization. Greecce: Scientific Association of Adult Education (in Greek).

Petrie, P. (2013). Social Pedagogy in the UK. Gaining a firm foothold. Education Policy Analysis Archives, 21(37), 1-16. https://doi.org/10.14507/epaa.v21n37.2013

Petrie, P., \& Cameron, C. (2009). Importing Social Pedagogy? In J. Kornbeck \& N. Rosendal Jensen (eds.), The Diversity of Social Pedagogy in Europe: Studies in Comparative Social Pedagogies and International Social Work and Social Policy, Vol. 7 (pp. 145-168). Bremen: Europäischer Hochschulverlag.

Petrie, P., Boddy, J., Cameron, C., Wigfall, V., \& Simon, A. (2006). Working with children in care: European perspectives. UK: Open University Press.

Schugurensky, D., \& Silver, M. (2013). Social pedagogy: historical traditions and transnational connections. Education Policy Analysis Archives, 21(35).

Social Educational Trust (2001). Social Pedagogy and Social Education: Formerly known as the Radisson Report. A Report of two Workshops held on 11th - 12th July 2000 and 14th - 15th January 2001 at the Radisson Hotel, Manchester Airport.

Stephens, P. (2013). Social Pedagogy: Heart and head. Germany: Europäischer Hochschulverlag.

ThemPRA (2019). Social Pedagogy Standards. Retrieved from: http://www.thempra.org.uk/social-pedagogy/key-concepts-in-socialpedagogy/thempras-diamond-model/ 